\title{
Laser Ignition of Pulverized Coals
}

\section{JOHN C. CHEN*, MASAYUKI TANIGUCHI, KIYOSHI NARATO, and KAZUYUKI ITO}

Hitachi Research Laboratory, Hitachi, Ltd., 7-1-1 Omika-cho, Hitachi-shi, Ibaraki-ken 319-12, Japan

\begin{abstract}
We present a novel experiment to study the ignition of pulverized coal. A dilute stream of particles is dropped into a laminar, upward-flow wind tunnel with a quartz test section. The gas stream is not preheated. A single pulse from a Nd:YAG laser is focused through the tunnel and ignites the fuel. The transparent test section and cool walls allow for optical detection of the ignition process. In this article we describe the experiment and demonstrate its capabilities by observing the ignition behavior of spherical, amorphous-carbon particles and two coals: an anthracite and a high-volatile bituminous coal. The ignition behaviors of the carbon spheres and the anthracite are as expected for heterogeneous ignition, while the mechanism of the bituminous coal is uncertain. Calculations are also presented to describe the physical behavior of a laser-heated particle, and the heat transfer and chemistry of heterogeneous ignition.
\end{abstract}

NOMENCLATURE

$A_{o} \quad$ preexponential factor in Arrhenius rate constant $\left(\mathrm{kg} \mathrm{m}^{-2} \mathrm{~s}^{-1}\right)$

$c_{p} \quad$ particle specific heat $\left(\mathrm{J} \mathrm{kg}^{-1} \mathrm{~K}^{-1}\right)$

$D$ binary self-diffusion coefficient of oxygen $=\alpha T_{R}^{1.75}\left(\mathrm{~m}^{2} \mathrm{~s}^{-1}\right)$

$D_{l} \quad$ diameter of laser beam at ignition point (m)

particle diameter $(\mathrm{m})$

activation energy in Arrhenius rate constant $\left(\mathrm{kJ} \mathrm{mol}^{-1}\right)$

energy of laser pulse $(\mathrm{J})$

convective heat transfer coefficient, evaluated in the limit where $\mathrm{Nu}=$ $h d_{p} / k_{g}=2$. Thus, $h=2 k_{g} / d_{p}\left(\mathrm{~W} \mathrm{~m}^{-2}\right.$ $\mathrm{K}^{-1}$ )

$k$ particle thermal conductivity $\left(\mathrm{W} \mathrm{m}^{-1}\right.$ $\mathrm{K}^{-1}$ )

$k_{g} \quad$ thermal conductivity of the gas in the boundary layer $\left(\mathrm{W} \mathrm{m}^{-1} \mathrm{~K}^{-1}\right)$

$M_{c} \quad$ molecular weight of carbon $\left(\mathrm{g} \mathrm{mol}^{-1}\right)$

$n \quad$ order of reaction $(-)$

$P \quad$ pressure $(\mathrm{Pa})$

$Q_{g} \quad$ rate of heat generation (W)

$Q_{l} \quad$ rate of heat loss (W)
$Q_{\text {laser }}$ fraction of average laser power which is intercepted by the particle

$$
=E_{\text {laser }} / \tau\left(d_{p} / D_{l}\right)^{2}(W)
$$

$\mathscr{R}$ universal gas constant $=8.314 \times 10^{-3}$ $\mathrm{kJ} \mathrm{mol}^{-1} \mathrm{~K}^{-1}$

$r \quad$ radial coordinate $(\mathrm{m})$

$S$ external surface area of the particle $=$ $\pi d_{p}^{2}\left(\mathrm{~m}^{2}\right)$

$T \quad$ temperature (K)

$t \quad$ time (s)

$V \quad$ particle volume $\left(\mathrm{m}^{3}\right)$

$y$ molar ratio of carbon consumption to oxygen consumption ( $\mathrm{mol} \mathrm{C} \mathrm{mol} \mathrm{O}_{2}{ }^{-1}$ )

\section{Subscripts}

$R \quad$ condition at particle surface, $r=R$

$\infty \quad$ free-stream or environment condition

\section{Greek Symbols}

$\alpha \quad$ constant derived from the correlation for the binary diffusion coefficient of oxygen $=9.25 \times 10^{-10}\left(\mathrm{~m}^{2} \mathrm{~s}^{-1} \mathrm{~K}^{-1.75}\right)$

$\Delta H_{c}$ heat of reaction per mass of carbon consumed $\left(\mathrm{J} \mathrm{kg}^{-1}\right)$

$\epsilon \quad$ particle emissivity (-)

$\chi \quad$ oxygen mole fraction $(-)$

$\lambda \quad$ wavelength of laser $(\mu \mathrm{m})$

$\rho$ particle density $\left(\mathrm{kg} \mathrm{m}^{-3}\right)$

$\sigma \quad$ Stefan-Boltzmann constant $=5.67 \times$ $10^{-8} \mathrm{~W} \mathrm{~m}^{-2} \mathrm{~K}^{-4}$ 
$\omega^{\prime \prime}$ molar flux of oxygen at the particle surface (mol $\mathrm{O}_{2} \mathrm{~m}^{-2} \mathrm{~s}^{-1}$ )

\section{INTRODUCTION}

Since the first systematic study by Faraday and Lyell [1] many experiments have been devised to examine pulverized-coal ignition. Most are described in the review by Essenhigh et al. [2]. The ignition behavior of clouds of pulverized fuel is of greatest interest to those concerned with the prevention of dust explosions (in coal mines or grain elevators, for example) and with flame stability in coal-fired combustors [3-5]. Such systems are difficult to analyze because of the coupling of solid-to-gas, solid-to-solid, and gas-to-gas in heat transfer and chemical reactions. This coupling is broadly known as the "cooperative mechanism" [3]. To analyze the results from cloud experiments and to extend them to other systems, it is first necessary to measure reaction parameters in single-particle or dilute-suspension experiments in order to eliminate the cooperative mechanism. However, even with these seemingly simple experiments (and data interpretation), many discrepancies exist in data obtained with different techniques $[2,6]$.

Among the various dilute-suspension experiments the most favored in recent times have been versions of the drop-tube furnace used by Cassel and Liebman [3]. A review of these experiments is beyond the scope of this article; we simply list as references those using versions of this technique [2,7-11]. Nearly all drop-tube experiments measure the minimum gas temperature that leads to ignition at various conditions. Application of an appropriate analysis then produces the ignition parameters (reaction order, kinetic rate constant). As mentioned earlier there are discrepancies between reaction parameters measured by these experiments,

Here, we report on a new experiment that relies on pulsed-laser ignition of a dilute suspension. We know of four other laser-based experiments [12-15], but only the latter three deal specifically with the ignition process, while the first one deals primarily with extinction. Our experiment, however, is most similar to that of Ref. 12. Laser ignition experiments offer the distinct advantage of easy optical access to the particles (because of the absence of a furnace or radiating walls), and thus permit direct observation and particle temperature measurement. At present, however, reaction parameters have not been reported from these experiments.

\section{EXPERIMENT}

Figure 1 shows a schematic of the laser ignition experiment; the inset shows the details around the test section. Sieve-sized particles are dropped through a tube into a laminar, upward-flow wind tunnel with a quartz test section. We do not preheat the gas. The gas flow rate is set so that the particles emerge from the feeder tube, fall approximately $3 \mathrm{~cm}$, and then turn and travel upward out of the tunnel. This ensures that the particles are moving slowly downward at the ignition point, chosen to be $1.5 \mathrm{~cm}$ below the feeder tube exit. A single pulse from a Nd:YAG laser is focused and deflected at an angle down through the test section. The beam is defocused upon exiting the test section, and two addition prisms fold the beam back through the ignition point. We estimate that less than ten particles are contained in the volume formed by the two intersecting beams. In this study the emission from the igniting particles is detected by a photomultiplier tube (PMT). A simple lens images an area $25 \mathrm{~mm}$ in diameter centered about the ignition point onto an optical-fiber bundle ( $5.5 \mathrm{~mm}$ diameter) which transmits the light to the PMT. Finally, a microcomputerbased data acquisition system records the signal.

The feeder is a capped cylinder (12 mm i.d.) with a tapered bottom connected to a $4-\mathrm{mm}$ tube. Within the feeder a wire mesh is suspended, and supports a mound of particles. A jolt to the feeder results in particles falling through the mesh and into the feeder tube. The jolt is provided by directing the exit of a pressurized solenoid valve at the feeder, and energizing the solenoid. For coal particles, we find that the optimum mesh in the feeder should be two mesh sizes larger than the finest through which the particles will pass. 


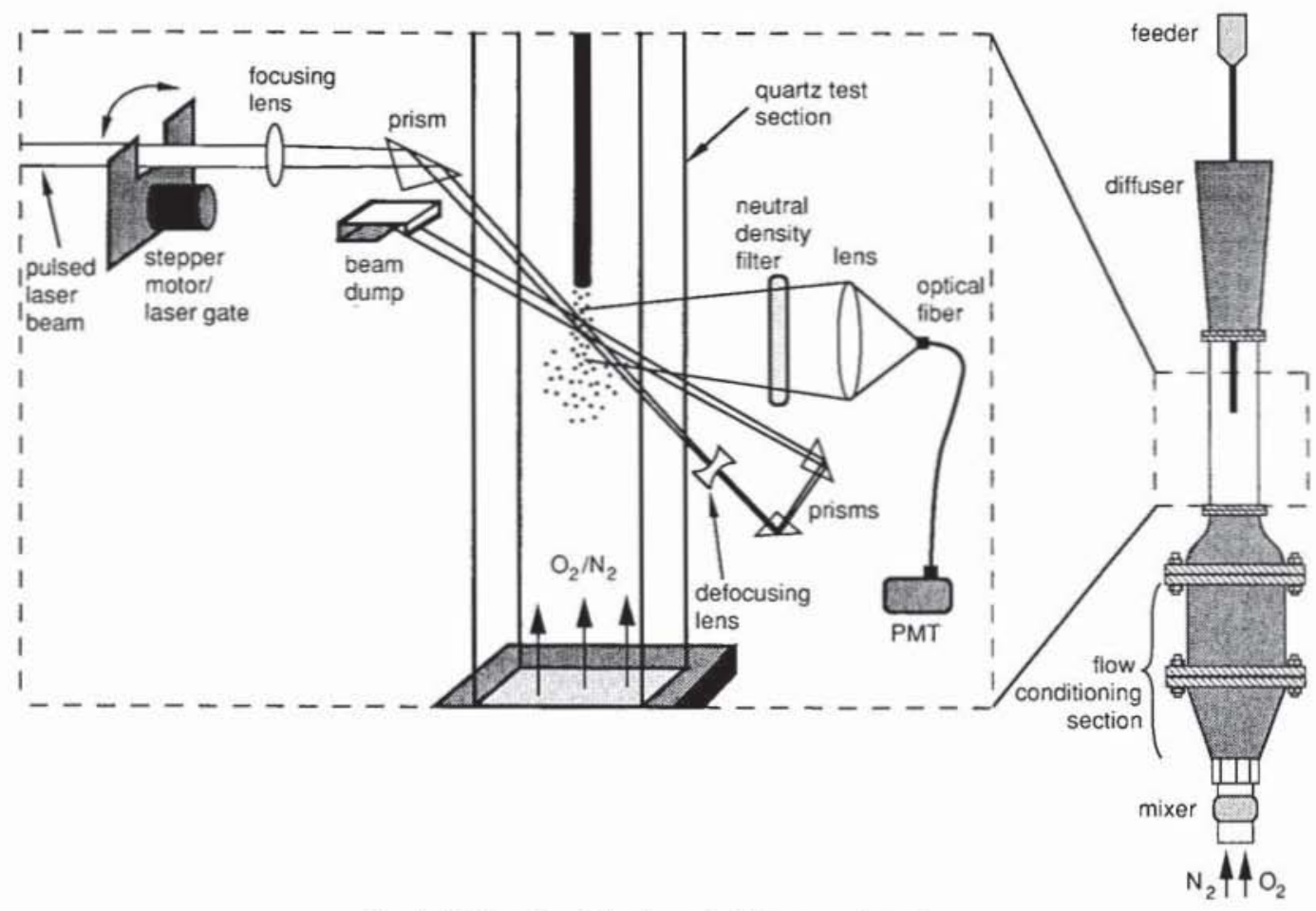

Fig. 1. Schematic of the laser ignition experiment.

The YAG laser operates at $5 \mathrm{~Hz}$ and emits a nearly collimated beam ( $8 \mathrm{~mm}$ diameter) in the near-infrared $(\lambda=1.06 \mu \mathrm{m})$. The laser pulse duration is $150 \mu \mathrm{s}$ (manufacturer's specification), and the energy is variable up to $740 \mathrm{~mJ}$ per pulse, with pulse-to-pulse fluctuations of less than $3 \%$. At the ignition point, the beam diameter normal to its propagation direction is $\sim 2.5 \mathrm{~mm}$ on each pass of the beam. A laser "gate" (see Fig. 1) is used to permit the passage of a single pulse to the test section. The gate is formed by cutting a wide slot in a piece of aluminum, and mounting it on a controlled stepper-motor. Prior to each experiment one edge of the gate blocks the laser pulses until the motor controller is triggered, causing the gate to rotate to the position shown in Fig. 1. After a set dwell-time, which permits the passage of the laser pulse, the controller is triggered again and rotated to block the succeeding pulses. By synchronizing both the solenoid valve and the stepper-motor controller with the laser, we can control the delay time between the firing of the feeder and the passage of the laser pulse. Heating the particles from two sides achieves more spatial uniformity, and allows for higher energy input than a single laser pass. By measuring the laser energy after each pass through the test section, we estimate that $60 \%$ and $40 \%$ of the laser energy arrive at the ignition point after the first and second passes, respectively. Finally, note that we use only neutral-density filters in the detection system. Thus, the PMT signal derives from emission at all wavelengths over which the PMT responds ( $\sim 300$ to $650 \mathrm{~nm}$ ).

We report here the ignition behaviors of spherical, amorphous-carbon particles and two coals. The carbon, known as Unibeads $\mathrm{C}$, is a commercially available product used as column packing material for gas chromatography. We believe it is similar to the Spherocarb particles widely used in other studies. It is sized to $-100 /+120$ mesh (136 $\mu \mathrm{m}$ average) by the manufacturer. The two coals are an Australian high-volatile (hv) bituminous (Newlands) and a Chinese anthracite (Sanxi), sized to $-100 /+$ 120 mesh $(136 \mu \mathrm{m})$ and $-150 /+170$ mesh $(96 \mu \mathrm{m})$. All samples are dried at $70^{\circ} \mathrm{C}$ under vacuum. The proximate analyses for the coals are listed in Table 1, along with ultimate analyses for all three samples. 


\section{TABLE 1}

Sample Analyses ${ }^{a}$

\begin{tabular}{lcccccccc}
\hline \multicolumn{1}{c}{ Sample } & $\begin{array}{l}\text { Volatile } \\
\text { Matter }^{b}\end{array}$ & Ash $^{b}$ & $\mathrm{C}^{c}$ & $\mathrm{H}^{c}$ & $\mathrm{O}^{c}$ (difn & $\mathrm{N}^{c}$ & $\mathrm{~S}^{c}$ \\
\hline $\begin{array}{l}\text { Unibeads C } \\
\begin{array}{l}\text { Newlands } \\
\text { hv bituminous }\end{array}\end{array}$ & $\mathrm{nm}^{d}$ & $\mathrm{~nm}$ & 96.0 & 1.2 & $\mathrm{~nm}$ & 1.7 & $\mathrm{~nm}$ \\
$\begin{array}{l}\text { Sanxi } \\
\text { anthracite }\end{array}$ & 6.3 & 14.7 & 84.5 & 5.1 & 6.8 & 3.1 & 0.5 \\
\hline
\end{tabular}

Analyses for coals performed on bulk, unsized sample.

${ }^{b}$ Weight percent (dry basis).

${ }^{c}$ Weight percent (dry, ash-free basis).

${ }^{d}$ Not measured.

\section{ANALYSIS OF A}

\section{LASER-HEATED PARTICLE}

In this section we describe the thermal behavior of a single particle heated by a laser pulse. Although we develop the analysis for a single particle, it is applicable to a dilute suspension of particles; that is, the behavior of each particle is independent of the others in the suspension. We believe this situation is applicable to our experiment. We also neglect any chemical reactions occurring in the particle and in the fluid surrounding the particle. In this case the approximation implies that the time prior to ignition is too short for significant reaction to occur.

The temperature distribution within a spherical particle is described by the conduction heat equation in spherical coordinates:

$$
\frac{1}{r^{2}} \frac{\partial}{\partial r}\left(k r^{2} \frac{\partial T}{\partial r}\right)=\rho c_{p} \frac{\partial T}{\partial t} \text {. }
$$

In Eq. 1 we have assumed temperature $T$ varies only in the radial direction $r$, and no heat generation in the particle (no chemical reaction). Equation 1 is solved subject to the following initial and boundary conditions:

$$
\begin{aligned}
& T(r, t=0)=T_{o}=300 \mathrm{~K}, \\
& \left.\frac{\partial T}{\partial r}\right|_{r=0}=0, \\
& Q_{\text {laser }}-\left.k S \frac{\partial T}{\partial r}\right|_{r=R}-h S\left(T_{R}-T_{\infty}\right) \\
& \quad-S \epsilon \sigma\left(T_{R}^{4}-T_{\infty}^{4}\right)=\left.\rho c_{p} V \frac{\partial T}{\partial t}\right|_{r=R} .
\end{aligned}
$$

Equation 2 states that at time $t=0$, the initial temperature distribution is uniform throughout the particle; Eq. 3 is the symmetry condition at the center of the particle; and Eq. 4 is the boundary condition applicable at the surface $(r=R)$. (The subscript, $r=R$, signifies that those terms containing it are evaluated for the particle surface condition.) Equation 4 states that the power input from the laser pulse minus the rate of energy loss (by conduction into the particle, and by convective and radiative heat loss) equals the rate of energy storage. Note that by setting $Q_{\text {laser }}=0$, Eqs. 1-4 describe the time-dependent particle temperature distribution after the laser is off.

Equations 1-4 can be solved by representing the particle as a network of concentric spherical shells, and then marching forward in time and space using an explicit, forward-difference scheme. The solution technique is given in most textbooks on conduction heat transfer; we follow the description by Incropera and DeWitt [16]. The solution is made more accurate by allowing the particle and gas conductivities, and the particle specific heat to vary with temperature. The values of these and other variables used in the calculation are: $\epsilon=0.8$; $\rho=1300 \mathrm{~kg} \mathrm{~m}^{-3} ; \quad k=1.412 \times 10^{-3} \mathrm{~T}+$ $1.245\left(\mathrm{~W} \mathrm{~m}^{-1} \mathrm{~K}^{-1}\right)[16] ; k_{g}=5.56 \times 10^{-5}\left[\left(T_{R}\right.\right.$ $\left.\left.+T_{x}\right) / 2\right]+1.04 \times 10^{-2}$ [13]; and $c_{p}$ is given by the correlation of Merrick [17].

Once the particle diameter is specified, $Q_{\text {laser }}$ is affected only by $E_{\text {laser }}$ and $D_{l}$. For the present calculations we use $Q_{\text {laser }} /\left(\pi d_{p}{ }^{2}\right)=$ $2.37 \times 10^{8} \mathrm{~W} \mathrm{~m}^{-2}$. This corresponds to our experimental condition with the laser energy at $700 \mathrm{~mJ}$ per pulse, and assuming, arbitrarily, that the particle absorbs $80 \%$ of the energy intercepted by its cross-section. The calculation is sensitive to the parameter $Q_{\text {laser }} /\left(\pi d_{p}{ }^{2}\right)$, which can only be determined with accurate values of the coal's physical properties, but our goal here is to illustrate the particle behavior.

Figure 2 shows the temperature distribution within a $136-\mu \mathrm{m}$ carbon particle uniformly heated on its surface by a laser pulse, and the subsequent distribution after the laser is off. The temporal and spatial temperature-distributions throughout the heating period of 150 $\mu$ s are depicted in Fig. 2a and show that, for such a large particle, a substantial gradient 


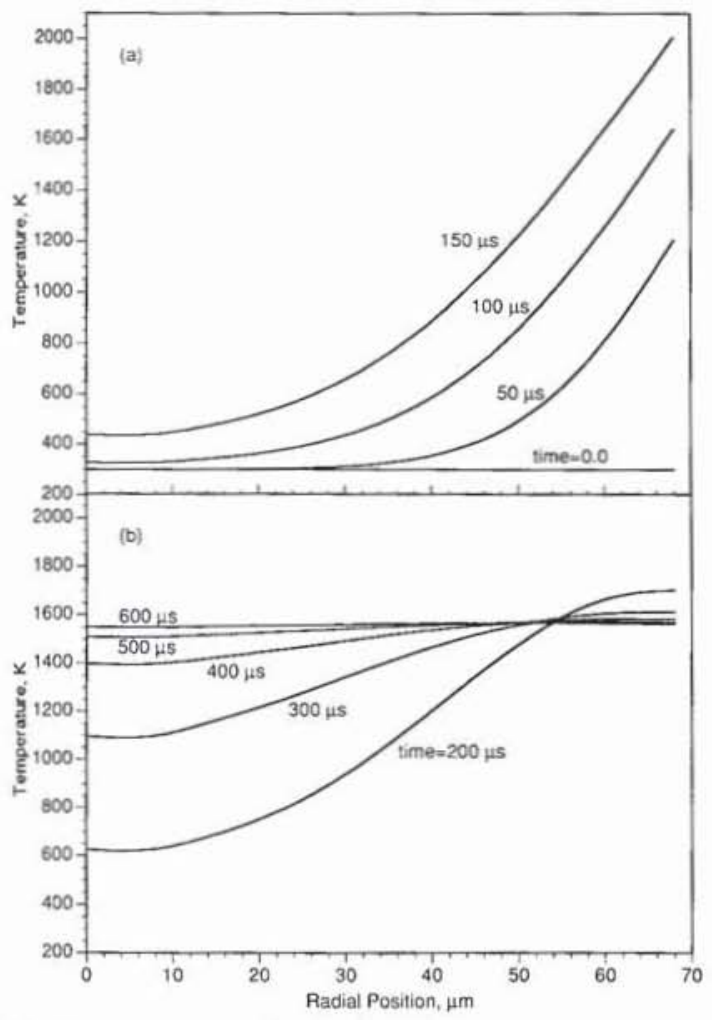

Fig. 2. Temperature distributions within a 136- $\mu \mathrm{m}$-diameter, amorphous-carbon sphere irradiated by a laser pulse of $150 \mu \mathrm{s}$ and energy flux of $2.37 \times 10^{8} \mathrm{~W} \mathrm{~m}^{-2}$. (a) Distributions during the heating period. (b) Distributions shortly after the laser is off at $t=150 \mu \mathrm{s}$.

exists. At the end of the heating phase the surface attains a temperature of $2000 \mathrm{~K}$, while the particle center is at $440 \mathrm{~K}$. The situation is less severe, with the gradients less steep and the center temperatures higher, with decreasing particle diameter.

Figure $2 \mathrm{~b}$ shows the distributions shortly after the heating phase (with $Q_{\text {laser }}$ set to zero), when the particle surface is undergoing convective and radiative cooling, and heat is conducted into the particle. It is seen that the surface temperature decreases rapidly and that, for even this large particle, the temperature equilibrates rapidly within the particle and reaches $1560 \mathrm{~K}$ in this case: Only $450 \mu$ s after the laser pulse (or $600 \mu \mathrm{s}$ from the start of the calculation), the center and surface temperatures differ by less than $20 \mathrm{~K}$. This behavior results from the rate of heat conduction within the particle being much higher than the rate of heat loss from the particle surface. For smaller particles the time needed for temperature equilibration decreases; for example, a $96-\mu \mathrm{m}$ particle equilibrates in $220 \mu$ s after the laser pulse. At times much longer than the heating pulse (not shown), the calculations show that the particle cools while maintaining a relatively uniform temperature distribution. Again, this results from the particle conductivity being greatly higher than the gas conductivity. Thus, decreases in surface temperature are rapidly equilibrated by conduction from within the particle.

This calculation for the particle thermal behavior is qualitatively substantiated by experimental observations of the ignition behavior of the amorphous-carbon spheres. A typical signal trace is shown in Fig. 3. The initial peak (arbitrarily set at $5 \mathrm{~ms}$ ) corresponds to the rapid surface heating caused by the laser pulse; the particle surface temperature is very high and the emission always saturates the PMT. The rapid drop in signal corresponds to the period after the laser is off, when surface temperature decreases rapidly (and while temperature is equilibrating within the particle). Ignition is seen by the second, slower rise in emission (or particle temperature) due to heat generation through chemical reactions. Finally emission decreases due, most likely, to extinction [12].

Note that, despite the appearance of the signal trace in Fig. 3, there does not exist a time delay between the initial emission peak due to surface heating and the second (ignition/combustion) peak. The apparent lack of signal during the $6 \mathrm{~ms}$ period after the initial peak results from the fact that the PMT excitation voltage is set very low. This was necessary to observe the entire peak of the second emission which results from a very high temperature. In other words, had the PMT excitation been set to a typical value, the two emission peaks of Fig. 3 would have appeared joined at some nonzero minimum in signal (see, for example, Fig. 6), and the second peak would have been cut off at $10 \mathrm{~V}$ due to PMT saturation.

It is difficult to unambiguously assign a particle heating rate in this experiment due to the nonuniform temperature distribution until equilibrium is reached. Nevertheless, if we define heating rate in this experiment as the 


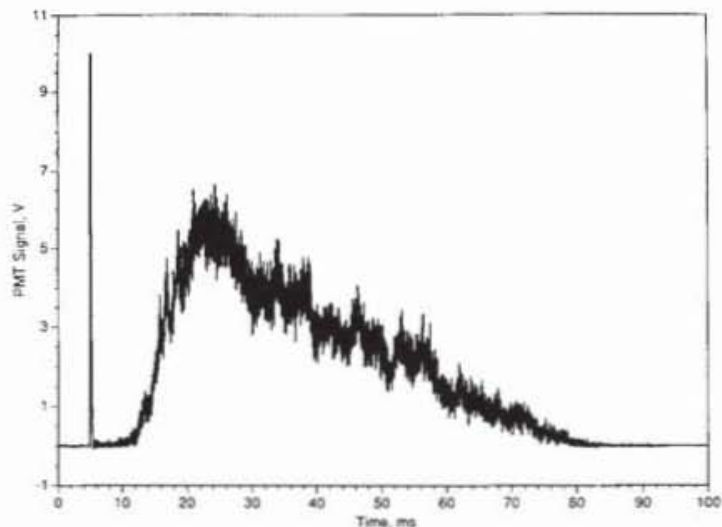

Fig. 3. Signal trace from the ignition of a $136 \mu \mathrm{m}$ carbon sphere in pure oxygen. Time $t=0$ is arbitrarily set to $5 \mathrm{~ms}$ prior to the first emission.

temperature that the particle attains after equilibration, divided by the time needed to reach equilibrium, we find that the rate is on the order of $10^{6}-10^{7} \mathrm{~K} \mathrm{~s}^{-1}$ for $80-160 \mu \mathrm{m}$ particles. This is approximately two orders of magnitude higher than drop-tube experiments, and more than ten times higher (by our estimate) than the laser-ignition experiment of Bar-Ziv et al. [13].

\section{THEORY OF}

\section{HETEROGENEOUS IGNITION}

The previous section shows that in our laser ignition experiment a particle can be rapidly heated by the laser pulse, but a large temperature gradient is sustained within the particle. The internal temperature equilibrates rapidly, however, because the rate of heat conduction within the particle is much higher than the rate of heat loss to the surroundings. Thus, we can simplify and model the process in this experiment to the following. A particle or collection of particles in a dilute suspension is instantaneously heated to some higher temperature by the laser pulse. (This simplification is justified by the short time needed to achieve temperature equilibration, which also justifies the neglect of reactions during this period.) The temperature attained is uniform throughout the particle and corresponds to that achieved after temperature equilibration within the particle. The particle behavior from this time forward is then determined by the balance between heat generation (due to chemical reactions) and heat loss.

The heat loss from the surface of a particle at temperature $T_{R}$ is the sum of the losses due to convection and radiation:

$$
\begin{aligned}
Q_{l} & =Q_{l, \text { conv }}+Q_{l, \text { rad }} \\
& =h S\left(T_{R}-T_{\infty}\right)+\epsilon \sigma S\left(T_{R}{ }^{4}-T_{\infty}{ }^{4}\right) .
\end{aligned}
$$

The radiative loss term is easily determined, and is relatively unimportant until the particle temperature exceeds $\sim 1500 \mathrm{~K}$. The convective loss term, however, is more difficult. Under conditions where the Reynolds number $(\mathrm{Re})$ is on the order of unity, as applicable in this experiment, a good approximation is to assume Nusselt number $(\mathrm{Nu})$ equals two, which leads to $h=2 k_{g} / d_{p}$. Thus, Eq. 5 can be rewritten, on a per-external-surface-area basis:

$$
\frac{Q_{l}}{S}=\frac{2 k_{g}}{d_{p}}\left(T_{R}-T_{x}\right)+\epsilon \sigma\left(T_{R}^{4}-T_{x}^{4}\right) .
$$

For the gas conductivity, $k_{g}$, in the boundary layer around a heated particle we use the relation (for air) recommended by Bar-Ziv et al. [13]:

$$
\begin{aligned}
k_{g}= & 1.04 \times 10^{-2} \\
& +5.56 \times 10^{-5}\left(\frac{T_{R}+T_{\infty}}{2}\right) \frac{\mathrm{W}}{\mathrm{mK}} .
\end{aligned}
$$

Equation 7 represents an approximation for the conductivity of air evaluated at the mean of the free-stream and particle-surface temperatures.

Following the development of Bar-Ziv et al. [13] the heat generated by a spherical carbon particle undergoing oxidation on its external surface is determined by the kinetic expression:

$$
\frac{Q_{g}}{S}=\Delta H_{c} \chi_{R}^{n} A_{o} \exp \left(-\frac{E}{\mathscr{R} T_{R}}\right)
$$

and the oxidant diffusion expression:

$$
\begin{aligned}
\frac{Q_{g}}{S}= & \Delta H_{c} M_{c} y \omega^{\prime \prime} \\
= & \Delta H_{c} M_{c} y \frac{5 P \alpha}{4 \mathscr{R} d_{p}}\left(\frac{T_{R}^{2}-T_{\infty}^{2}}{T_{R}^{1.25}-T_{\infty}^{1.25}}\right) \\
& \times\left(\chi_{\infty}-\chi_{R}\right) .
\end{aligned}
$$


Equation 9 differs from Ref. 13 and is derived by solving the steady-state, one-dimensional equation of mass diffusion, assuming a perfect gas and using the correlation of Ref. 13 for the dependence of the binary diffusion coefficient on temperature. Also used to derive Eq. 9 is the temperature profile in the static boundary layer surrounding a heated particle obtained by solution of the one-dimensional, steady-state heat equation with a temperature-dependent gas conductivity.

It is useful now to examine the behaviors of $Q_{g} / S$ and $Q_{l} / S$, since this will guide us in establishing the ignition criteria. In Fig. 4 are plots of these heat rates as a function of particle temperature. They are generated by use of the values listed in Table 2. Figure 4 shows that heat loss increases steadily with temperature at first but accelerates rapidly above 2000 $\mathrm{K}$ due to the strong temperature dependence of radiative loss, and that heat generation (calculated for $n=0.5$ and 1) has the sigmoid shape. Note that the kinetic parameters $A_{o}$ and $E$ (see Table 2) are chosen to be in the range of values found in Ref. 18, and that, for simplicity, the same values are used to calculate $Q_{g} / S$ for reaction orders of 0.5 and 1 . Though this is strictly not correct, our purpose is to illustrate the behavior. Focusing on the curve corresponding to $n=0.5$ (for example), one interpretation of this plot is as follows. A particle uniformly heated to a final temperature below $1600 \mathrm{~K}$ will cool off immediately since below this temperature heat loss is

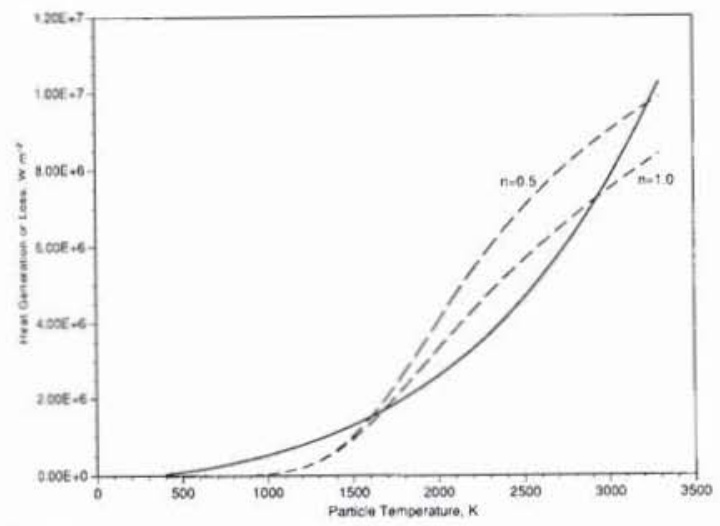

Fig. 4. Rates of heat loss (solid curve) and heat generation (dashed curves) per external surface area. The parameters used are listed in Table 2.

\section{TABLE 2}

Parameters Used to Generate Fig. 4

$$
\begin{aligned}
T_{x}= & 300 \mathrm{~K} \\
\mathrm{P}= & 10^{5} \mathrm{~Pa} \\
d_{p}= & 136 \mu \mathrm{m} \\
\epsilon= & 0.8 \\
D= & 2 \times 10^{-5}\left(\frac{T_{R}}{300}\right)^{1.75} \mathrm{~m}^{2} \mathrm{~s}^{-1} \\
\chi_{x}= & 1.0 \\
k_{g}= & 1.04 \times 10^{-2}+5.56 \\
& \times 10^{-5}\left(\frac{T_{R}+T_{x}}{2}\right) \mathrm{W} \mathrm{m}^{-1} \mathrm{~K}^{-1} \\
y= & 2{\mathrm{~mol} \mathrm{C} \mathrm{mol} \mathrm{O}^{-1}}_{\Delta H_{c}=} 9210 \mathrm{~kJ} \mathrm{~kg}^{-1} \\
& \left(\text { for the reaction of } \mathrm{C}+\frac{1}{2} \mathrm{O}_{2} \rightarrow \mathrm{CO}\right) \\
A_{\mathrm{o}}= & 100 \mathrm{~kg} \mathrm{~m}^{-2} \mathrm{~s}^{-1} \\
E= & 83.7 \mathrm{~kJ} \mathrm{~mol}^{-1}
\end{aligned}
$$

greater than heat generation. If the particle is heated to above $1600 \mathrm{~K}$, however, its temperature will continue to increase, since heat generation is now greater than loss. It will finally attain a temperature of $3200 \mathrm{~K}$, at which the two heat rates are just balanced. In this example, therefore, it is obvious that ignition occurs when the particle is heated to above $1600 \mathrm{~K}$. We define this ignition condition - when a particle is heated to a temperature at which the heat generation rate exceeds the loss rate-as noncritical ignition. This definition differentiates the situation from that in the typical hotgas, drop-tube experiment-defined as critical ignition condition-in which the free-stream gas temperature is varied to find the minimum gas temperature needed for ignition. The effect of varying the gas temperature is to shift the $Q_{l} / S$ curve relative to the $Q_{g} / S$ curve, and at the critical ignition condition the heat loss curve is tangent to the lower portion of the heat generation sigmoid.

At the critical ignition condition, it can be shown [2] that both $Q_{g} / S=Q_{l} / S$ and $d Q_{g} /$ $d T_{p}=d Q_{1} / d T_{p}$ must be satisfied. Then, from the measured gas temperature at critical ignition under various experimental conditions (varying $d_{p}$ and $\chi_{\infty}$ ), the particle's temperature at the critical ignition point and the ignition rate constant can be determined. In our laser experiment free-stream gas temperature is fixed, so we cannot achieve critical ignition. Therefore, in order to extract rate constants, 
we must measure the ignition temperature (1600 K in Fig. 4) for various $d_{p}$ and $\chi_{\infty}$, and use it in the criterion that $Q_{g} / S=Q_{l} / S$ at the ignition temperature.

For a fixed particle size, there exists a unique value of $\chi_{\infty}$ for which the particle's thermal behavior in this experiment is as depicted in Fig. 5a. In this example the heat generation curve intersects the heat loss curve at one unique temperature $(2100 \mathrm{~K})$ and, thus, the criteria $Q_{g} / S=Q_{l} / S$ and $d Q_{g} / d T_{p}=d Q_{l} /$ $d T_{p}$ are satisfied at this temperature. However, this situation represents the extinction condition since any disturbance around this point will lead to a decrease in temperature. It is interesting to note, however, what Fig. 5a suggests for the laser ignition experiment in this scenario: A particle heated by the laser pulse to any temperature above $2100 \mathrm{~K}$ will cool

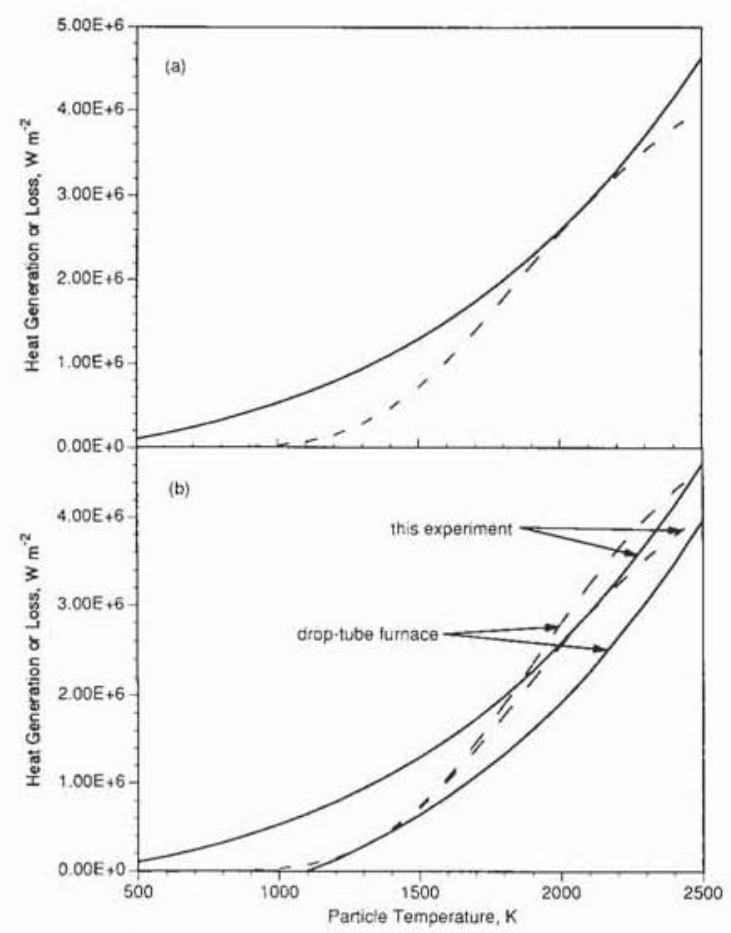

Fig. 5. (a) Rates of heat loss (solid curve) and heat generation (dashed curve) per external surface area under extinction condition. Reaction order, $n$, is 0.5 and the other parameters are as listed in Table 2 except that $\chi_{\infty}=0.53$. (b) Differences in ignition behavior under extinction condition of this experiment and under critical ignition condition in the drop-tube furnace. Curves for this experiment are described in (a). Heat rates for the drop-tube furnace are calculated for $\chi_{\infty}=0.53$ and $T_{\infty}=1110 \mathrm{~K}$. down to $2100 \mathrm{~K}$, and then remain at this temperature since the heat generation and heat loss rates are exactly balanced. Thus, theoretically, we can find this extinction condition, but it would provide little kinetic information compared to the critical ignition condition of drop-tube experiments. The explanation for this is depicted in Fig. 5b, in which the heat generation and loss curves for a drop-tube experiment at the critical ignition condition are overlayed on Fig. 5a. The gas temperature in this case is $1110 \mathrm{~K}$ and $\chi_{\infty}$ is the same as for Fig. 5a. It can be seen that the ignition point (at $1320 \mathrm{~K}$ ) of the drop-tube experiment lies in the low-temperature, kinetics-controlled regime, while the extinction point of our laser experiment is in the high-temperature, diffusion-controlled regime.

We end this section with some comments regarding our observations and the above calculations. First, we note that the maximum surface temperature attained during laser heating is much higher than the final equilibrated temperature, which is also the ignition temperature if the particle ignites. The question then is why the particle does not ignite during the laser heating period, as it is heated to temperatures well above the ignition point? The answer may be that the heating period of $150 \mu \mathrm{s}$ is too short for significant reaction to occur, or that ignition cannot be sustained because heating is confined to the surface, and the bulk of the particle has undergone little reaction. Regardless of the reason, it is clear from Fig. 3 that ignition does not occur until after the laser heating period and, by our calculation, after temperature equilibration.

Regarding the previous calculations we note that, as Bar-Ziv et al. [13] point out, the explanation given for Fig. 4 represents a simplification of the actual situation. After ignition, physical properties of the particle change due to reaction, and the heat generation and loss curves will shift in response to these changes. In addition, we make use of the steady-state assumption between the rates of oxygen diffusion and reaction on the particle surface. This assumption is questionable since there may not be sufficient time to achieve steady state before ignition occurs. And finally, we note that the choice of the assumed combustion product 
condition. Ignition is defined, in this case, as the appearance of subsequent emission (as detected by the PMT) after the first emission due to laser heating. It is seen that for the hv bituminous coal in pure oxygen the $96-\mu \mathrm{m}$ sample is more readily ignited (lower laser energy for a given probability or higher probability at a given energy) than the $136-\mu \mathrm{m}$ particles. Though not shown here, the anthracite and carbon spheres show this same trend. Also, note that higher laser energy is needed to achieve the same ignition probability when the oxygen level is reduced for a fixed particle size, as expected. We were unable to ignite either size of the hv bituminous coal, the most reactive of the three samples, in air. Finally, comparing the distributions between the anthracite and the hv bituminous coal under otherwise identical conditions, it is obvious that their ignition reactivities are widely different.

\section{DISCUSSION}

Pulverized coal particles can ignite either heterogeneously or homogeneously [2]. Previous experiments have shown that the ignition mechanism is dependent on coal type $[11,14$, 20]. Furthermore, modeling efforts have predicted a transition in ignition mechanism with changes in particle size and/or oxygen concentration [21, 22]. The theory for heterogeneous ignition is well developed, but at present no theory has been put forth to analyze cases of homogeneous ignition. The main difficulties are the uncertainty and complexity in depicting the devolatilization process and the computational burden of homogeneous reactions. (Gururajan et al. [23] present a theory of homogeneous ignition, but at present the uncertainties in the many model parameters render it impractical for extracting ignition rate parameters from experimental data.)

The low volatile-matter content of the Unibeads $\mathrm{C}$ particles suggests that its ignition mechanism should be heterogeneous. This is supported by the signal trace of Fig. 3, which shows only a single broad emission and no secondary peaks due to homogeneous reactions. By the same argument of low volatile matter we expect the anthracite to ignite heterogeneously, and this too is supported by the single ignition/combustion emission in Fig. 6a. The ignition mechanism of the hv bituminous coal, containing a large amount of volatile matter, is not established. The emission characteristic of this coal (Fig. 6b) suggests that one of the two broad peaks is due to heterogeneous reactions, and the other to homogeneous reactions. We are developing diagnostics to determine the ignition mechanism of this coal and the sources of the emissions.

The ignition probability distributions are similar to those reported by researchers using hot-gas, drop-tube experiments $[6,10,11]$; there, the probability of ignition increases continuously as the gas temperature increases. We observe such distributions for all three samples reported here. They are easily explained by noting the existence of distributions in size, density, specific heat, ash content, and chemical reactivity among the particles in any sample.

Heterogeneous ignition theory applied to a single particle shows that ignition temperature must increase with decreasing particle size. Thus, the fact that smaller particles are shown here to ignite more readily than larger particles may at first seem contradictory, at least for the anthracite and carbon spheres which presumably ignite heterogeneously. This is reconciled by noting that, for a given laser energy flux (or power density), a smaller particle will be heated to a higher equilibrated temperature, as shown by our calculations for amorphous-carbon spheres. Figure 8 is a plot of these temperatures for the three particle sizes

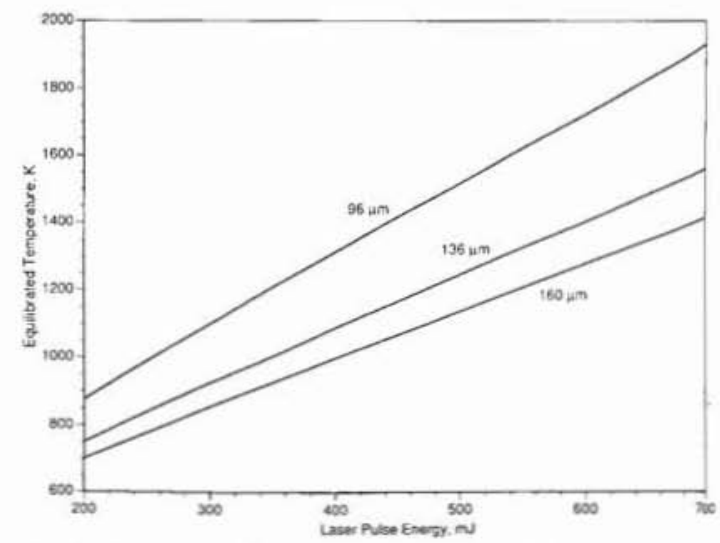

Fig. 8. Equilibrated temperatures attained by laser-heated carbon spheres of various sizes. 
used in this study. We suspect that coal particles show the same behavior, and that the increase in temperature attained (at a fixed laser energy) for a smaller particle more than offsets the increase in ignition temperature. This is consistent with previous measurements under critical $[7,11]$ and noncritical $[20]$ conditions that show a $30-100-\mathrm{K}$ increase in particle ignition temperature when particle size is reduced from 150 to $100 \mu \mathrm{m}$; Fig. 8 predicts temperature increases of more than $200 \mathrm{~K}$ for such a size decrease.

In order to extract kinetic information from our experiment and to allow for comparison of results with other experiments, additional information must be experimentally determined. Toward this goal we are developing a two-color pyrometry system for direct measurement of the particle ignition temperature. Used in conjunction with the analyses for non-critical ignition, we will be able to extract reaction parameters.

\section{REFERENCES}

1. Faraday, M., and Lyell, C., Philos. Mag. 26:16-35 (1845).

2. Essenhigh, R. H., Mahendra, K. M., and Shaw, D. W., Combust. Flame 77:3-30 (1989).

3. Cassel, H. M., and Liebman, 1., Combust. Flame 3:467-475 (1959).

4. Seeker, W. R., Lester, T. W., and Merklin J. F., Rev. Sci. Instrum. 51(11):1523 (1980).

5. Hertzberg, M., Fuel 70:1115 (1991).

6. Wall, T. F., Gupta, R. P., Gururajan, V. S., and Zhang, D., Fuel 70:1011-1016 (1991).
7. Bandyopadhyay, S., and Bhaduri, D., Combust. Flame 18:411-415 (1972).

8. Karcz, H., Kordylewski, W., and Rybak, W., Fuel 59:799 (1980).

9. Fu, W., and Zeng, T., Combust. Flame 88:413-424 (1992).

10. Zhang, D., Wall, T. F., Harris, D. J., Smith, I. W., Chen, J., and Stanmore, B. R., Fuel 71:1239-1246 (1992).

11. Boukara, R., Gadiou, R., Gilot, P., Delfosse, L., and Prado, G., Twenty-Fourth Symposium (Intemational) on Combustion, The Combustion Institute, Pittsburgh, 1993, pp. 1127-1133.

12. Ubhayakar, S. D., and Williams, F. A., J. Electrochem. Soc. 123(5):747-756 (1976).

13. Bar-Ziv, E., Jones, D. B., Spjut, R. E., Dudek, D. R., Sarofim, A. F., and Longwell, J. P., Combust. Flame 75:81-106 (1989).

14. Zhang, D., Combust. Flame 90:134-142 (1992).

15. Phuoc, T. X., Mathur, M. P., and Ekmann, J. M., Combust. Flame 93:19-30 (1993).

16. Incropera, F. P., and DeWitt, D. P., Fundamentals of Heat Transfer, Wiley, New York, 1981, p. 214.

17. Merrick, D., Fuel 62:540-546 (1983).

18. Wall, T. F., and Gururajan, V. S., Combust. Flame 66:151-157 (1986).

19. Mitchell, R. E., Twenty-Second Symposium (Intemational) on Combustion, The Combustion Institute, Pittsburgh, 1988, pp. 69-78.

20. Tomeczek, J., and Wojcik, J., Twenty-Thind Symposium (International) on Combustion, The Combustion Institute, Pittsburgh, 1990, pp. 1163-1167.

21. Annamalai, K., and Durbetaki, P., Combust. Flame 29:193-208 (1977).

22. Lau, C., and Niksa, S., Combust. Flame 90:45-70 (1992).

23. Gururajan, V. S., Wall, T. F., Gupta, R. P., and Truelove, J. S., Combust. Flame 81:119-132 (1990).

Received 5 April 1993; revised 22 November 1993 